\title{
Extractions Morphotectonic Features Using Satellite Data Processing and DEM-Derived Spatial Models
}

\author{
Rayan Gh. Thannoun ${ }^{1}$, Hadeer Gh. M. Adeeb ${ }^{2}$ and Azealdeen S. Al-Jawadi ${ }^{3 * *}$ \\ Remote Sensing Center, University of Mosul, Mosul, Iraq \\ Dams and Water Resources Research Center, University of Mosul, Mosul, Iraq \\ College of Petroleum and Mining Engineering, University of Mosul, Mosul, Iraq \\ Correspondence: azealdeenaljawadi@uomosul.edu.iq
}

\begin{abstract}
Received: $\quad$ Morphotectonic features were investigated in the Shireen anticline, which is located in the 12 August 2021 Kurdistan region of northern Iraq to get more insight into the effect of the tectonic activity on this anticline. For deducing and illustrating the morphotectonic features of the anticline, some

Accepted:

29 October 2021 digital processing methods have been applied to the part of the image of Landsat in which this anticline appears, and using the Digital Elevation Model. The results explained the

Published:

31 January 2022 identification of such morphotectonic features such as faults, joints, and flat irons topography, and then updated the structural style of the anticline by identifying and drawing the inferred morphotectonic features. The tectonic activity was evaluated in terms of applying longitudinal profiles analysis to some selected valleys in both limbs of the anticline. Consequently, the prominence of knick points in the bottoms of the selected valleys reflects the existence of sudden slopes. Therefore, the southwestern limb of the anticline was suffered more tectonic uplifting activity, and this is clear from the appearance of the triangular shapes in the central part of this limb towards the southeastern plunge of the anticline.
\end{abstract}

Keywords: Shireen anticline; Image filtering; Principal component analysis; Morphotectonic; Longitudinal profile analysis; Knick points

\section{Introduction}

Earth topography evolves as a result of the response to surface processes driven by impact multi-criteria, for example, climatic origins and tectonic forces (Champagnac et al., 2012; Whittaker, 2012). These processes react directly and consistently with the surface of the earth and reflecting subtle variations in topography. The relationships between topography, surface processes, tectonic setting, and landforms revealed the variations in the rate, direction, and deformation style of the tectonic history. Morphotectonic features represent major elements in high relief and tectonically active regions; hence, they demand sufficient detection and extraction to estimate the impact of tectonic activity on the landforms. According to (Mahmood et al., 2014; Hamdoon et al., 2021), morphotectonic features are controlled by some factors in the mountainous region; this includes the relative tectonic uplift rates, translational, and upright motions (Agard et al., 2005; Othman and Jadda, 2020; Znad et al., 2020). These factors specify the essential relationship of stream incision with the rock resistance to erosion (Anderson and MacGregor, 1998). Both remotely sensed techniques and Digital Elevation Model (DEM) offer a valuable contribution to morphotectonic studies. Remotely sensed data are widely used in

DOI: $10.46717 /$ igj.55.1A.7Ms-2022-01-26 
morphotectonic study for the accurate and fast determination and extraction of the morphotectonic features. In this context, the advantage of remote sensing data representing by providing comprehensive information for large areas, the ability to map inaccessible areas, multispectral recordability, and suitable digital processing of the obtained data, etc. (Kaya and Tüysüz, 2015). On the other hand, DEM is a digital depiction of surface topography or terrain; it can be expressed as a raster or as an irregular network of triangular. DEM products are often derived in GIS, as well as the most general basis for digitally-created relief or terrain maps. The present study aims to extract the morphotectonic features of the Shireen anticline by applying some morphotectonic analysis and then discussing the tectonic setting of the extracted features. However, this study focuses on the morphotectonic imprints on the morphology, streams, and topographic variations of the Shireen anticline.

\section{Study Area, Location, and Geological Setting}

The area of study is located in the north part of Iraq and is bordered by Latitudes $37^{\circ} 03^{\prime} 00^{\prime \prime} \mathrm{N}$ and $36^{\circ} 56^{\prime} 00^{\prime \prime} \mathrm{N}$ and Longitudes $43^{\circ} 53^{\prime} 00^{\prime \prime} \mathrm{E}$ and $44^{\circ} 07^{\prime} 00^{\prime \prime} \mathrm{E}$. It covers an area of $\sim 587.5 \mathrm{~km} 2$. The study area is existing near the Barzan sub-district, which is followed by the Mergasur district in the Erbil Governorate-Kurdistan Region of Iraq Fig. 1.
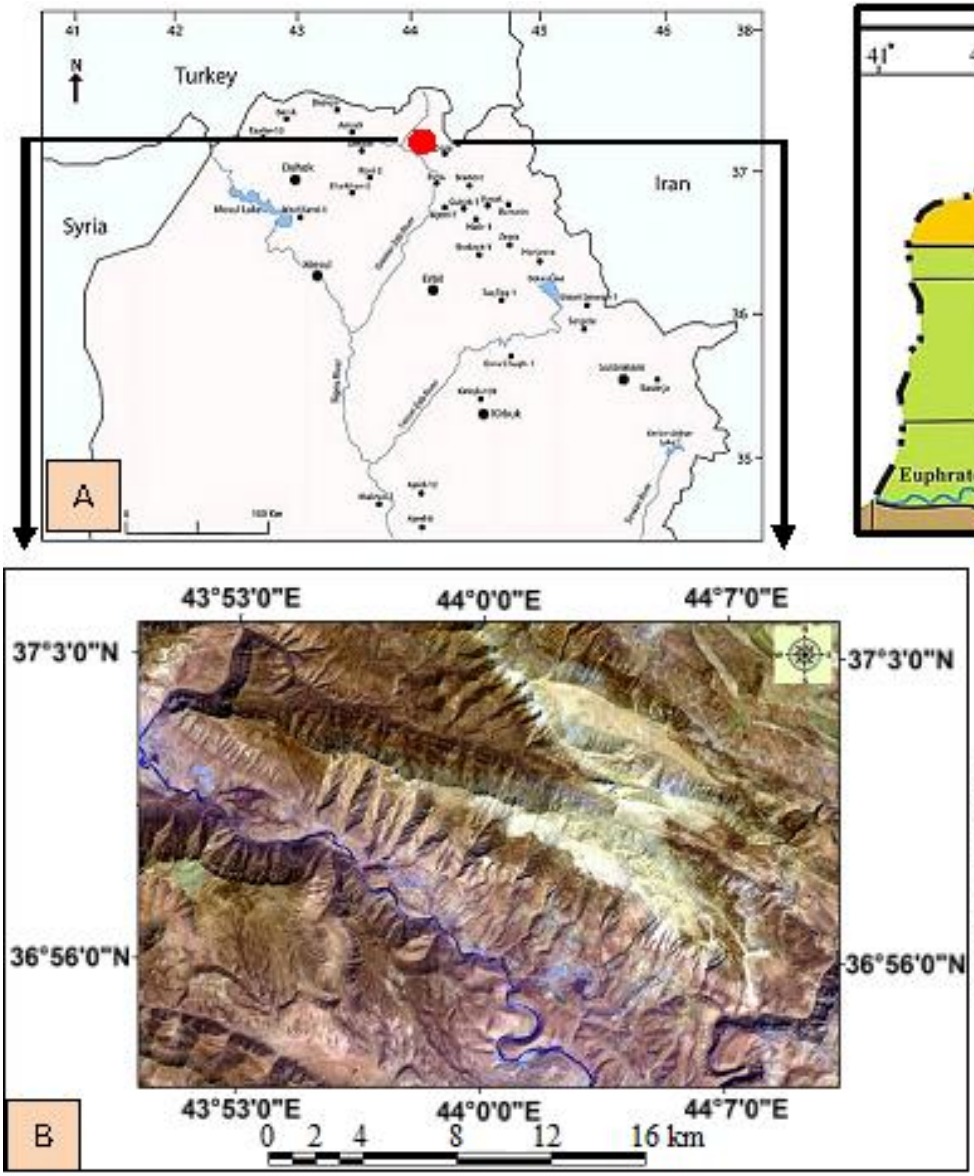
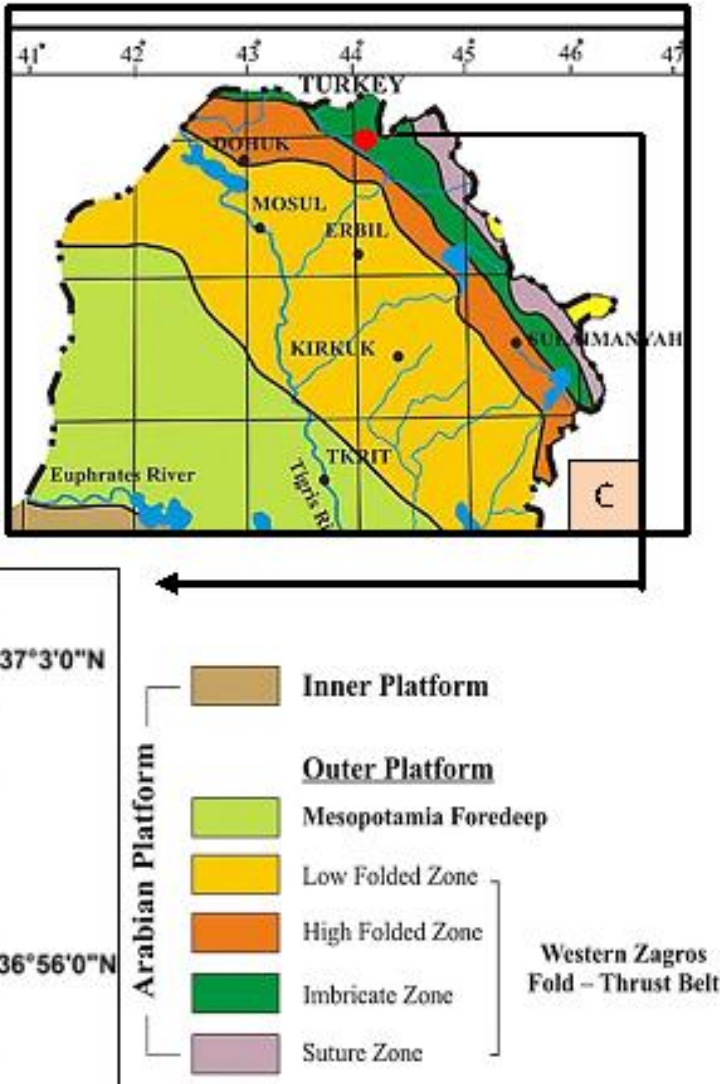

Fig. 1. Geographic location-A, aerospace vision-B, and tectonic location of the Shireen anticline-C (Fouad, 2015)

The geological setting of the Shireen anticline is describing briefly depending on the five principal elements: tectonic, structural geology, geomorphology, topography, and stratigraphy. Tectonically, according to Fouad (2015); Alavi (2004); Berberian (1981); Ramsey et al. (2008), the Shireen anticline is located in the Imbricated zone which is part of the Arabian Plate Outer Platform within the Thrust Belt 
of Zagros Fold Fig. 1-C. Referring to the structural geology, the Shireen anticline is an asymmetric double plunging with the fold axis trends towards northwest-southeast. The southeastern part of this anticline is plunging into the Shakui River while the northwestern one is plunging into the Ava Shin River. These two parts are very steep and truncated by an undulating escarpment. Geomorphologically, the area under investigation is a mountainous region, which is characterized by high rugged scarps and steep slopes. In this context, elevation ascending towards the central part of the anticline forms rugged topography along a lot of parts and with some depression parts, which was formed due to the existence of parallel and semi-parallel valleys. Stratigraphically, the exposed formations in the Shireen anticline are ranged from Lower Cretaceous to Recent age. According to (Jassim and Goff, 2006), these formations beside the main Quaternary Deposits are described briefly from the younger to older as follow:

\subsection{Balambo Formation}

The Balambo Formation (Valaginian-Turonian) in the Shireen anticline is intensively deformed and consists of well-bedded limestone and marly limestone. Along the strike in the core of the Shireen anticline, the Balambo formation shows a diagnostic lithological variation to the Qamchuqa formation.

\subsection{Qamchuqa Formation}

This formation is considered one of the widest spread formations in Iraq return to the Early Cretaceous (Early Aptian - Early Cenomanian). In the study area, Qamchuqa Formation forms the carapace of the Shireen anticline especially in the core area and consists of grey, massive limestone, and dolostone.

\subsection{Aqra - Bekhme Formation}

The age of this formation returns to (Late Campanian-Late Masstrichtian), and also considers the most widespread in the northern parts of Iraq. Outcrops of the Aqra-Bekhme Formation in the study area include limestone and dolostones and cover most parts of the anticline's limbs.

\section{Methodology}

The method of the study is based on the following analytical approach that includes extracting information from digital image processing and the results obtained from analyzing the data of the DEM. Besides, more deducing the effect of the tectonic activity on the landforms in the Shireen anticline, Fig. 2 illustrates the main elements of the study method and the aspect used in the morphotectonic analysis.

\subsection{Data Preparation and Correcting}

Raw satellite images do not represent the true reflectivity of ground targets because they are subjected to some distortion during the scanning process and then converted into digital data. So, it requires an initial correction stage called primary processing or data restoration. In this stage, the data are corrected geometrically and spectrally through pre-processing methods. The geometric correction has been applied because the spatial location of the ground target in the image does not apply accurately to its real location on the ground (Wang et al., 2012). Therefore, in this study, the processing of the Landsat image was used by the registration method of an image to map type, which is defined to be a geometrical matching processing of a satellite image with a topographical map. This is to be done to remove the geometric distortions in the image assuming that the map is the reference (Ton and Jain, 1989), and some of the Ground Control Points (GCP) were selected in a topographic map with the same points in the corresponding Landsat image. In this context, manual geometrical matching depends on 
choosing Ground Control Points (GCP) that are symmetric in the image and map. In general, one of the advantages of manual geometrical matching is that it achieves high accuracy when the image contains prominent features. Based on that, the coordinate control points that represent the permanent properties of targets were chosen, i.e., the properties that do not change with the change of time and the change of the spectral band in which the image was captured, for example (the confluence of valleys and the edges of geomorphological shapes, ext..). After completing the previous process, the image was spectral corrected and all atmospheric effects were removed by applying (Fast Line-of-sight Atmospheric Analysis of Spectral Hypercubes-FLAASH) atmospheric correction model correction modular in environmental visualization image- ENVI software. After completing the previous process, the image was spectrally corrected and all atmospheric effects were removed.

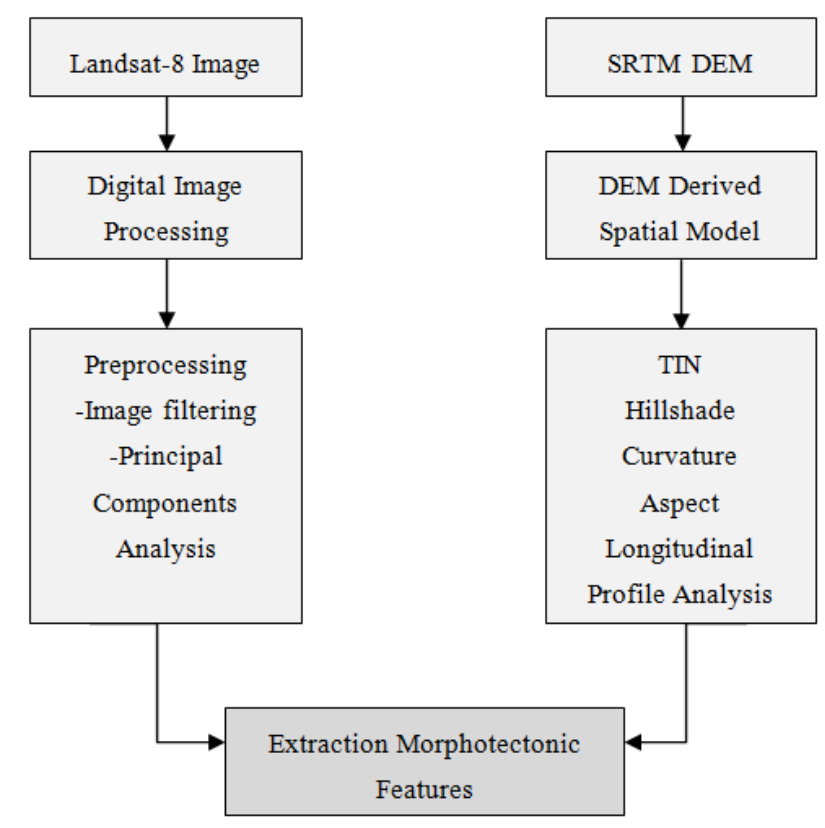

Fig. 2. The flowchart shows the methodology of the study

\subsection{Extraction of Morphotectonic Features by Satellite Processing}

Post-processing digital methods of remotely sensed data are considered a modern technique that widely used in various fields such as topographical surveys, environmental and engineering studies, and in geological studies related to exploring the earth minerals and oil resources and determining geological structures such as folds and faults as well (Mather and Koch, 2011). The importance of this technique is to extract spectral information in the region of the visible part of the spectrum, and other information located in spectral ranges that the human eye cannot see, such as the near and middle infrared and thermal fields. In this study, the processing has relied on features extraction in the Shireen anticline through the following two methods:

\subsubsection{Image filtering}

Image filtering is a set of methods in which the ground features are improved by conducting a complete separation of the boundaries that represent the ground targets to be detected (Fawwaz et al., 2018). The main objective of the filtering techniques is to process a specific image so that the result is more appropriate than the original image, and the application of processing is depended on the target to be detected. The digital processing by the filtering method aims to increase the information that can be interpreted visually from the data, and thus the filtering process can be considered as a science and art in which the role of the human is reflected in terms of choosing the type of required filter and its 
parameters. The functions of image processing in the spatial domain can be expressed in the following formula (Ismail, 2014):

$$
g(x, y)=T[A(x, y)]
$$

Where $A(x, y)$ is the input image, $g(x, y)$ is the processed output image, and $\mathrm{T}$ is a factor influencing $\mathrm{A}$ and an identifier in the neighborhood of $(x, y)$. It is possible to make a $\mathrm{T}$ effect on a group of input images, as in the application of collecting elements ( $\mathrm{k}$ pixels). The method used to define a neighborhood around an $(x, y)$ element is to use a square or rectangular sub-window with an $(x, y)$ center. The center of the sub-image moves from one element to another, for example, from the upper left corner, and applies the location to that position of $(x, y)$ to give the result $g$ at that position. Although other neighborhood shapes such as a circle are sometimes used. The square matrix is the most widely used due to its easy implementation. The simplest form of $\mathrm{T}$ is when the dimensions of the neighborhood are $(1 * 1)$. In this case, $g$ depends on the value of $\mathrm{A}$ only, and $\mathrm{T}$ becomes the function of gray level transformation and is called the mapping function as in the following equation:

$$
S=T[(r)]
$$

For simplicity, we use the symbols ( $\mathrm{r}$ ) and (S) as two sequences indicating the gray level $A(x, y)$ and $g(x, y)$ at the point $(x, y)$. If the isolated point is in a location outside the center of the window, the sum will be different from zero as well, but the response will be weaker. These responses can be removed by comparing the sum with a specific threshold. If we make (w1, w2,.., w3) represent the window parameters, taking into account the eight neighbors of $(x, y)$, we can generalize the previous discussion by performing the following process in the neighborhoods of $(x, y)$ with a dimension of $(3 * 3)$. There are two types of Kernel filters, smoothing (low pass filter) and differentiating (High pass filter). The elements of the smoothing kernel filter sum to one and create an averaging of the values in all local neighborhoods. Consequently, this type of Kernel filter reduces the effect of noise (Al-Amri et al., 2010). Elements of differentiating Kernel filter sum to zero and reveal the places where the pixels are changing fastly in value and is, therefore, useful to extract edge information. In the area under investigation, the borders or edges of the landforms of the Landsat image have been enhanced through a kernel high pass filter with a window of $(3 * 3)$ according to the following parameters, Table 1.

Table 1. Kernel filter parameters

\begin{tabular}{ccc}
\hline $\mathbf{0}$ & $\mathbf{1}$ & $\mathbf{0}$ \\
\hline-2 & 0 & 0 \\
0 & 0 & 0 \\
\hline
\end{tabular}

The output image of the spatial filtration process (Fig. 3) shows the enhancing of morphotectonic features in both limbs of the Shireen anticline. The joints groups are concentrated in the hard limestone layers of the Balambo Formation, specifically along the southwestern limb of the anticline, further, it is noted that the joints are less concentrated in the northern limb. Some unidentified faults, which were unindicted in the previously geological reports of the Shireen anticline, have been observed depending on the visual interpretation of the filtered image. These faults were divided, depending on their extensions and type, into major reverse faults extending over long distances and their planes are parallel and diagonal to the axis of the fold. Their effects were drawn on the image (Fig. 4). While the faults of short extensions, their existence is limited to the outcrops of the Balambo and Qamchuqa Formations, and they are characterized by being short extensions than the first one, leading to the displacement of some layers and this is what led to be explained. 


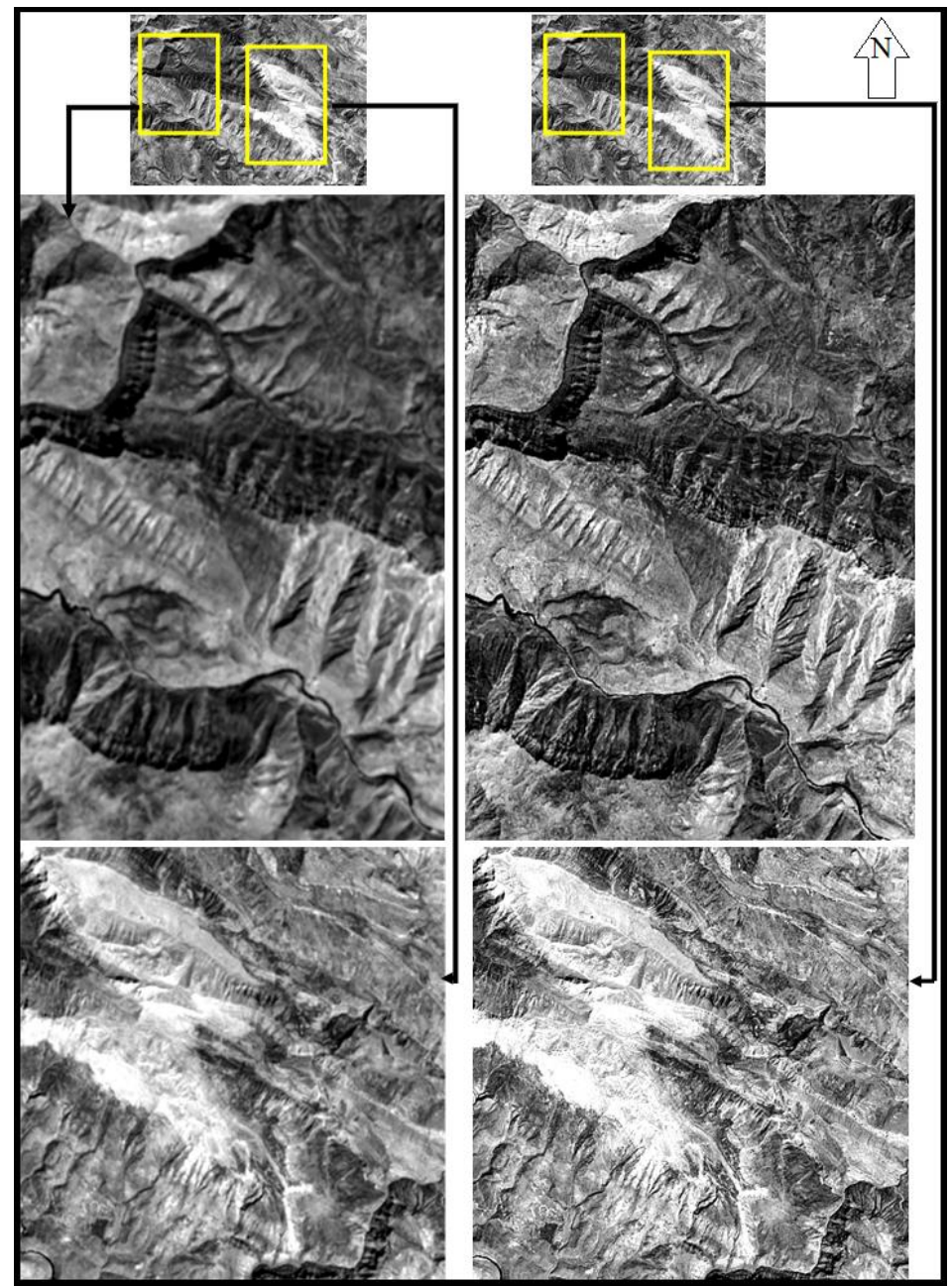

Fig. 3. Filtered output image of the study area
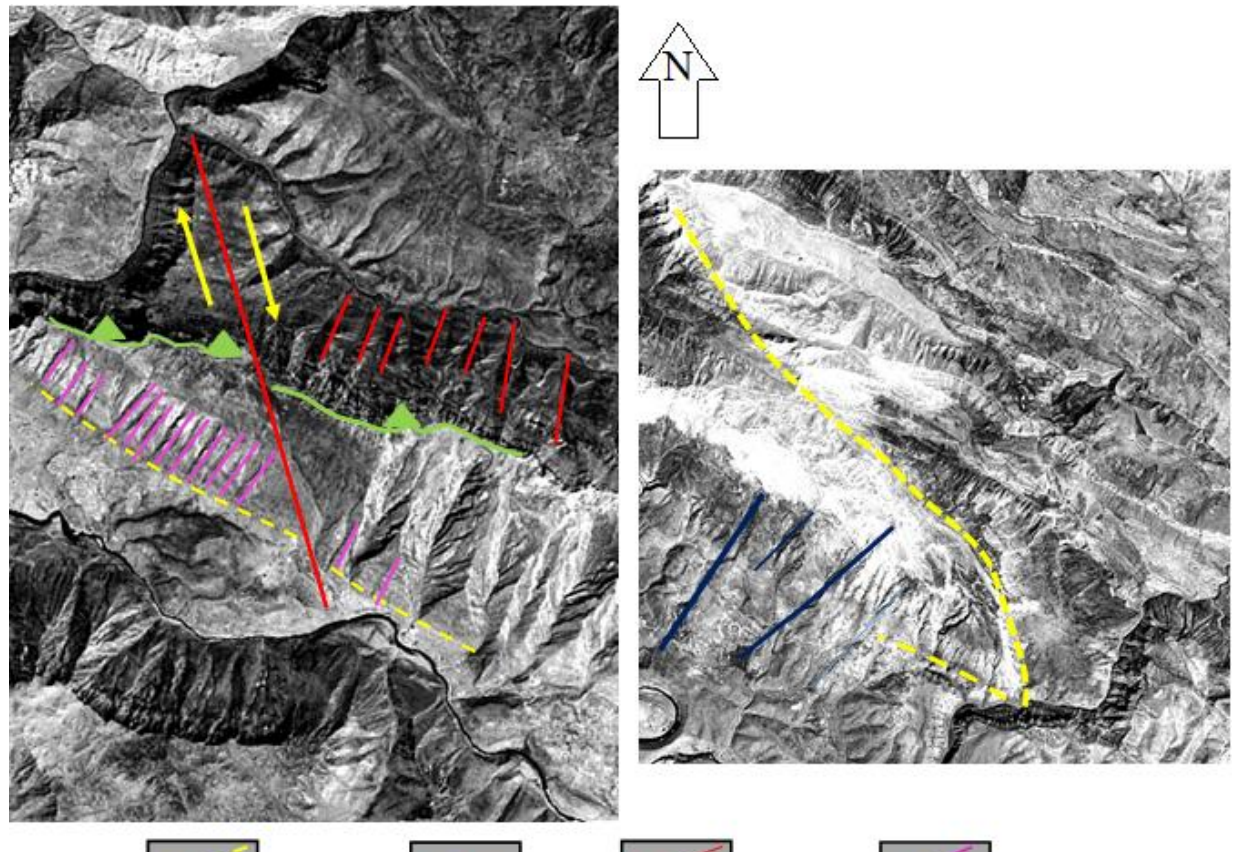

Thrust Fault Cliff
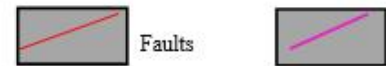

Joints

Fig. 4. Structures inferred from image filtering 


\subsubsection{Principal components analysis $(P C A)$}

The remote sensing data represent the electromagnetic radiation of the ground targets, which is recorded in a digital number format. The amount of reflectivity from the features or the ground targets is close in some spectral bands i.e. in many cases; there is a similarity in the reflection coefficient of the ground targets in the different bands of spectrum. This indicates that objects with spectral properties different from their neighbors will have difficulty distinguished because of their propagation and also the dominance of prominent and repeated spectral properties materials on other infrequent spectral properties materials. Based on the hitherto mentioned, the image is subject to special processing by the interpreter of remote sensing data to disconnect between spectral bands to illustrate new ground targets (Thannoun, 2012). The principal components analysis is one of the important processing used in statistical studies to simplify large amounts of data by converting many closely related variables into a smaller number of variables not related to each other and are called principal components (Abdu, 2019). The mechanics of this type include the linear transformation on each band ( $\mathrm{N}$ dimensions) image, and then creating ( $\mathrm{N}$ new) non-correlated components depending on the axis of greatest variance, (Alexandris et al., 2017), (Caixeta, 2016) (Fig. 5).

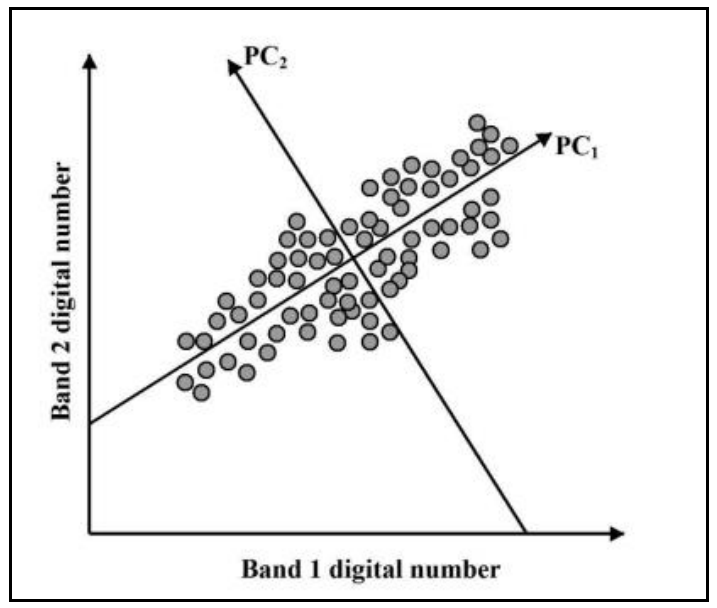

Fig. 5. The spatial relationship between the first two principal components (Caixeta, 2016)

As shown in Fig. 5, a new coordinate system can be chosen in which the first main axis (the first component) is the axis on which the data are collected $\mathrm{Y} 1$ and the second axis $\mathrm{Y} 2$ is perpendicular to the first main axis. This transformation is done using the following mathematical relationship (Mather and Koch, 2011):

$$
\begin{gathered}
Y_{1}=a_{11} x_{1}+a_{12} x_{2} \\
Y_{2}=a_{21} x_{1}+a_{22} x_{2}
\end{gathered}
$$

Where $\mathrm{x} 1, \mathrm{x} 2$ are the coordinates of the imaging unit in the original system (pre-processing). $\mathrm{Y} 1$, $\mathrm{Y} 2$ are the coordinates of the imaging unit in the new system (after-processing). The values a11, a12, a21, a22 are the conversion constants. The method of principal component analysis will result in dividing the images into several components. In this context, the main and repeated data are saved in the first component (PC1), which contains a very high percentage of the total data, and the second component (PC2) contains a fewer amount of data. While the other components (especially the third and fourth) contain less data than represented by minute spectral changes, so the images of the principal components resulting from this process are less correlated. This method was used in the digital processing of Landsat-7 images captured in 2001 used in this study. It was applied to spectral bands (1, 
2, 3, 4, 5, and 7) to extract the largest amount of information and as an attempt to enhance and distinguish the geomorphological units in the area. Fig. 6-A to F, show the principal components of the spectral bands.
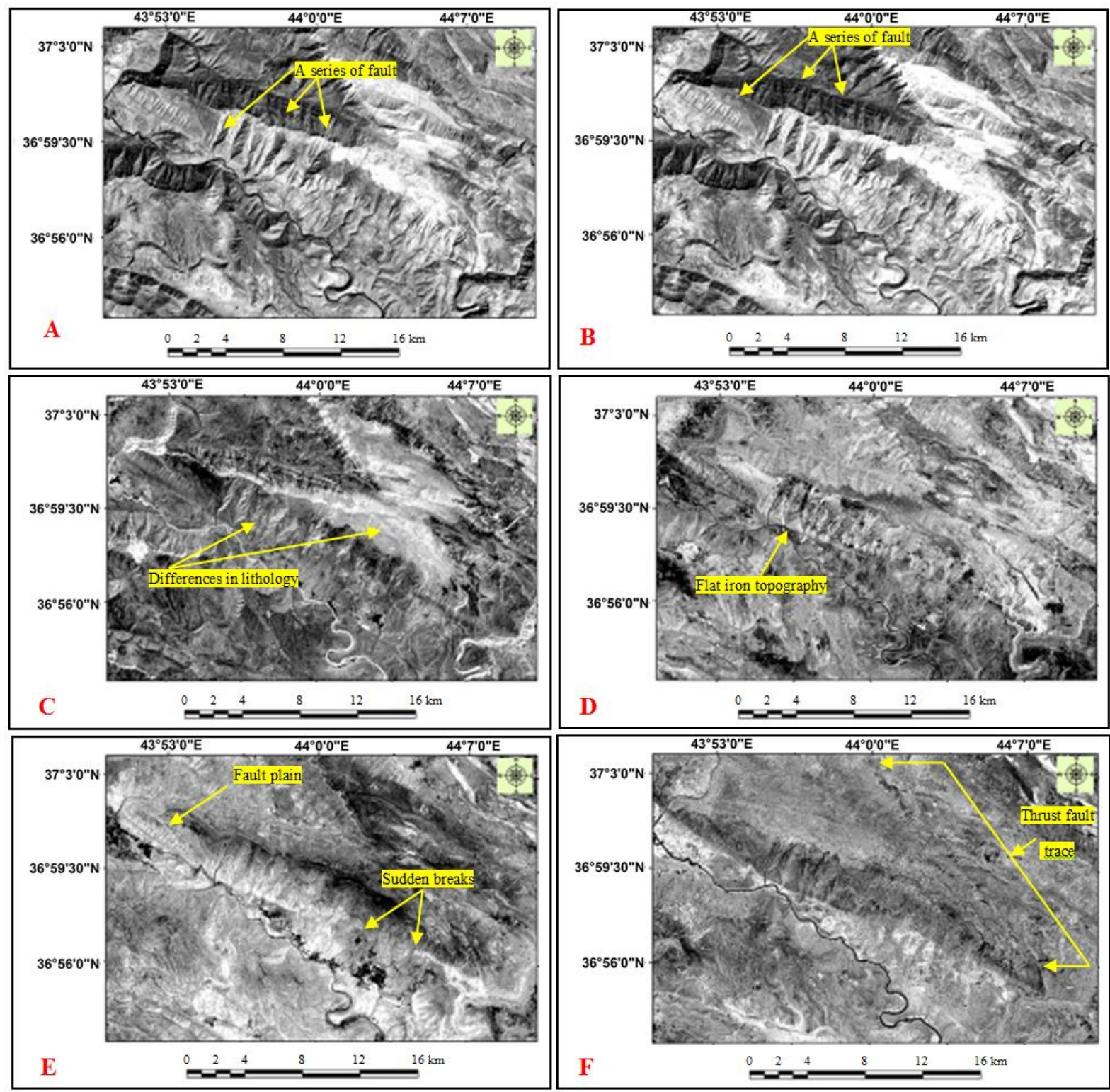

Fig. 6. Principal components analysis

The spectral information was concentrated in the first component, Fig. 6 A, which clarified the main geomorphological features such as the borders of the anticline, structural ridges unite, and the central core unit. It provides a clear view of the density and degree of erosion that is relatively different in parts of the study area as well. In the second component, the spectral information of the geomorphological features starts to diminish, which is reflected in the specific geomorphological units within the geological structures and corresponds to a slight increase in the information of the flat areas (Fig. 6 B). In the last four components (Fig. $6 \mathrm{C}$ to F), a significant decrease in the intensity of the visible spectral information of the image is observed, and thus ground targets appear to reflect geomorphological phenomena that were not clearly distinguished in the first components. It can be explained by the interpretation of the six components, which shows the effect of the reverse fault along the southwestern limb towards the northeastern limb (Fig. 6 F), and the displacement of some layers due 
to the inferred strike-slip faults. Consequently, the processing images were combined by the principal components analysis into one image and giving each image one of the primary colors (PC2R, PC4G, PC6B). False color composite provides collecting data in one image for more than one field and color displaying, consequently, distinguishing a large amount of information (Fig. 7). It is noted in the southwestern limb that there is high clarification of layers influent by the referred faults, in addition to easy identifying extensions of some faults in the core of the anticline and some parts of the northeastern limb. As shown also in Fig. 7, it can be seen that the Shireen anticline can be divided into three regions according to the morphotectonic characteristics. Zone $\mathrm{A}$ is represented by the part of the anticline that is slightly affected by tectonic uplifts (especially in the southern limb). With the transition to zone B, we can notice the clarity of the triangular facets that reflect the effect of the tectonic uplift in this zone. Furthermore, the increase in the effect of faults, while the zone $\mathrm{C}$ has been affected by a high-intensity of tectonic uplift and the rate of erosion in this area has increased due to the presence of the thrust fault.

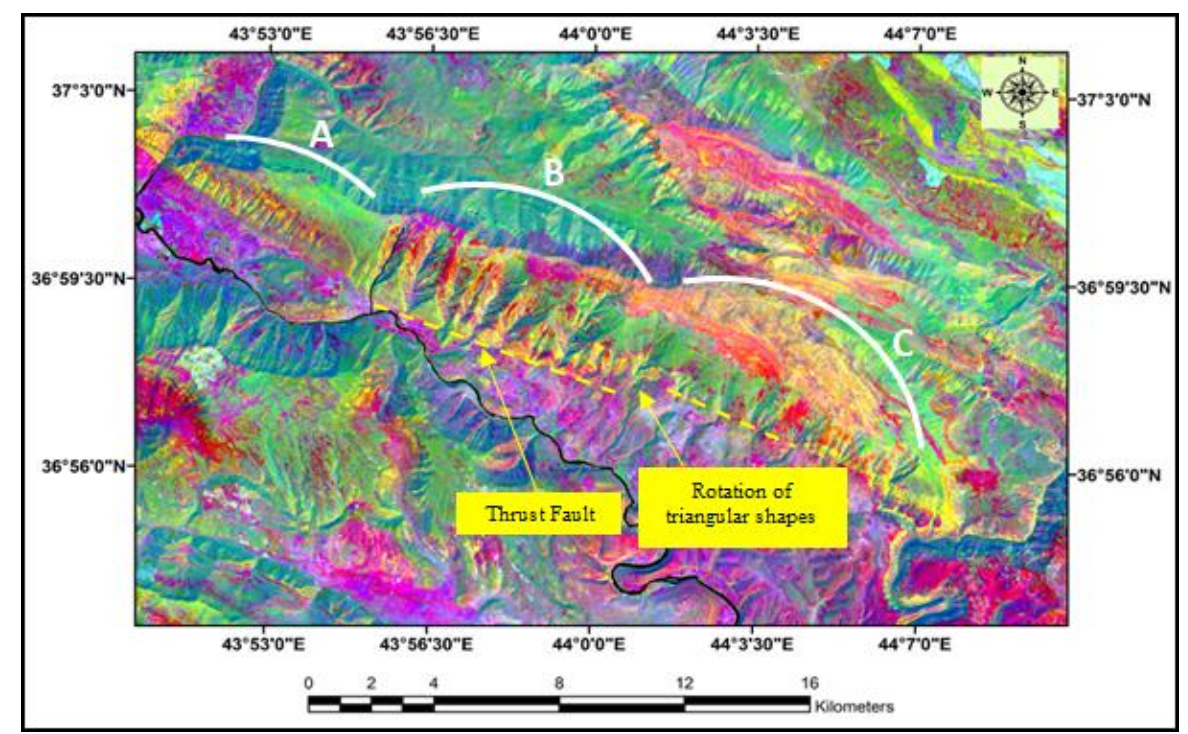

Fig. 7. False-color composite of principal component image

\section{Extractions Morphotectonic Features using DEM-Derived Spatial Models}

The DEM is considered one of the important tools and modern applications in which the topographical features are analyzed and presents a three-dimensional view of the terrain, which provides enormous applied potentials in the field of geomorphological and morphotectonic studies (Lakshmi and Yarrakula, 2018). The study relied on SRTM data of arc second with a resolution of 30 meters. GIS software was used in inputting, analyzing, and outputting the digital elevation data of the Shireen anticline. This software is distinguished by its ability to organize, analyzing, collecting, storing, managing, and displaying in special-purpose maps. The derivation of the morphological features of the study area using the DEM will highlight the morphological characteristics of the slopes of the study area and determines the influence of the tectonic activity on the topographical features by using models derived from the (DEM). All characteristics of the general topographical features in the study area were extracted from the results of the analysis of the DEM. This model represents the basis of modern geomorphological studies to extract information related to geomorphological and morphotectonic features. Four spatial models, such as triangles irregular networks (TIN), hillshade, aspect, and curvature modulus were relied on, in addition to analyzing some longitudinal profiles of selected valleys. According to what was mentioned above, the following are a presentation of maps, discussion of inferred information from these maps, and their relationship to the morphological situation of the study area: 


\subsection{Triangular Irregular Networks (TIN)}

TIN is a form of the data used in Geographic Information Systems to represent specified ground surfaces. It is a spatial network made up of interconnected triangles, each of the vertices of these triangles is known as coordinates and is considered as a method for modeling some shapes and elements to facilitate the process of studying it mathematically (Vivoni et al., 2004). TIN is a vector-based representation of the physical surface of the earth or the seafloor. This representation consists of nodes and lines with three-dimensional coordinates, which are organized in a network of triangles that do not coincide with each other, and after the build-up of the triangular network, it can calculate the height of any point by an integral operation using $\mathrm{X}, \mathrm{Y}, \mathrm{Z}$ coordinates of the interconnected triangle vertices to each other (Liu and $\mathrm{Wu}, 2020$ ). TIN is derived from the elevation data obtained from the contour map. The importance of these maps is to divide the study area into distinct terrestrial units according to the heights of each cell in the area and highlights the variation through the color grading. Fig. 7 represents an image output of topographical heights using the TIN. This Figure is deduced by observing the low and high topography of the classified area. For distinguishing and analyzing the features of topographical elevations, the elevation zones were determined for obtaining a classified output image. Each zone was given a particular color composed of specific proportions of each of the main colors according to a directive perspective. Therefore, it became easy to make a visual interpretation and determine the relation changes, particularly in areas with low terrain. This processing was adopted consistently with the geomorphological units deduced in this study. As shown in Fig. 8, the elevation zones were represented by several categories, the range between 450-677 meters occupied the low altitude, thus, the low point in the area was represented by the river valley bed. valley bottom runs parallel to the southern limb). The high elevation is between 2044-2272 meters in the areas located in some parts of the core of the Shireen anticline, while this height was not observed in other places of the anticline. To confirm the effect of the tectonic uplift in this zone, the parts of the syncline between the Shireen anticline and the other anticline located to the northeast regress in this higher elevation zone of the Shireen anticline and the other anticline. Likewise, the effect of faults on the topographical features in the southwestern limb of the Shireen anticline is noticeable from the variant undulated heights in the elevation zones between $905-1588$ meters.

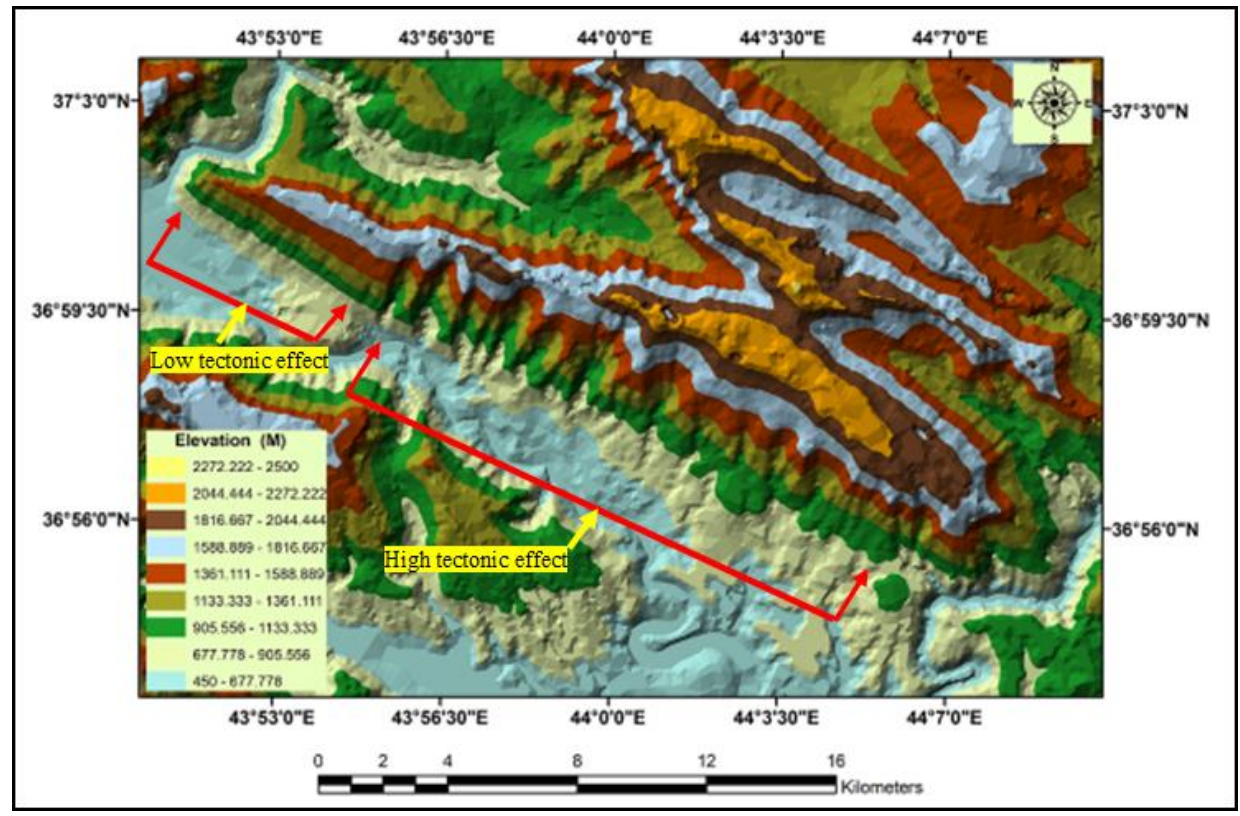

Fig. 8. Triangular irregular network map of the study area 


\subsection{Hillshade Map}

The processing of the DEM can cause virtual illumination to the surface by directing light or brightness to each pixel cell and then calculating the effect of brightness on neighboring cells (Biland and Çöltekin, 2017). The hillshade map results in the estimate of the intensity of lighting from the cells that cover the digital elevation image, which represents the ground units at the level of each cell by giving it a degree of shade i.e. grayscale value. These values start from the number 0 and end with the number 255 and this type of map determines which parts of the earth's surface will be shaded by another part of the earth's surface. To highlight the geomorphological units and inspection of the drainage pattern networks in the study area, four known azimuth directions (north - south - east - west) were chosen. The hillshade output images revealed that there are low shade areas, medium shade areas, and areas with large shade. Depending on Fig. 9, the most important morphometric properties can be summarized:

\subsubsection{Image with directions south (Azimuth 200 - Altitude 45)}

The southwestern parts of the Shireen anticline have been illuminated through the image. The use of this direction in illumination was accompanied by increased clarification of some lineaments represented by the faults cutting the southwestern limb, as well as the clarification of the thrust faults extending diagonally from the axis of the Shireen anticline.

\subsubsection{Image with direction south (Azimuth 45-Altitude 20)}

The application of this direction led to illuminate the northeastern limb of the Shireen anticline. The output images in the direction of (360) also clarify the parts of the syncline between the Shireen anticline and the structure to the northeast by shadowing its parts and separating the low areas from the other uplifted areas. There is also a further clarification in the fracture zones in the northeastern limb of the anticline specifically in the parts located near the northwestern plunge of the anticline, which was previously referred to in Fig. 4.

\subsection{Aspect Map}

Orientation is a simple visual process to compare all the neighboring points of an area in the DEM and determine any direction that follows the slope surface apparent in that area. The orientation helps to know the extent of the slope directions, and measured in degrees clockwise from the direction of the north and is similar to the compass (Ruibo and Weiming, 2009). The process of orientation can identify the slope zone direction that starts from zero in a clockwise direction until it completes a full rotation of 360-degree, and the slope direction can be monitored for any part of this cycle. The importance of orientation in geomorphological studies, especially morphotectonic, comes through knowing the sudden slope directions due to the tectonic processes in the region and the associated geological structures such as joints and faults. Also, the orientation helps in identifying the geomorphological units of different heights through the distribution of solar brightness resulted from this processing. From Fig. 10, it is noticed that the slopes in the southwestern limb and some areas of the northwestern limb of the anticline comprise sudden slope directions that correspond to the inferred faults, Fig. 4. The southeast direction (157.5-202.5) forms one of the patterns of sudden direction in the southwestern limb, which reflects a series of faults in this part, and this direction also corresponds distinctively with the thrust fault, which extends to the parts in the northeastern limb of the anticline. While the northwest direction (292.5-337.5) is considered the distinct sudden direction of the specified fault zones in the part of the anticline located on the northeastern limb. 


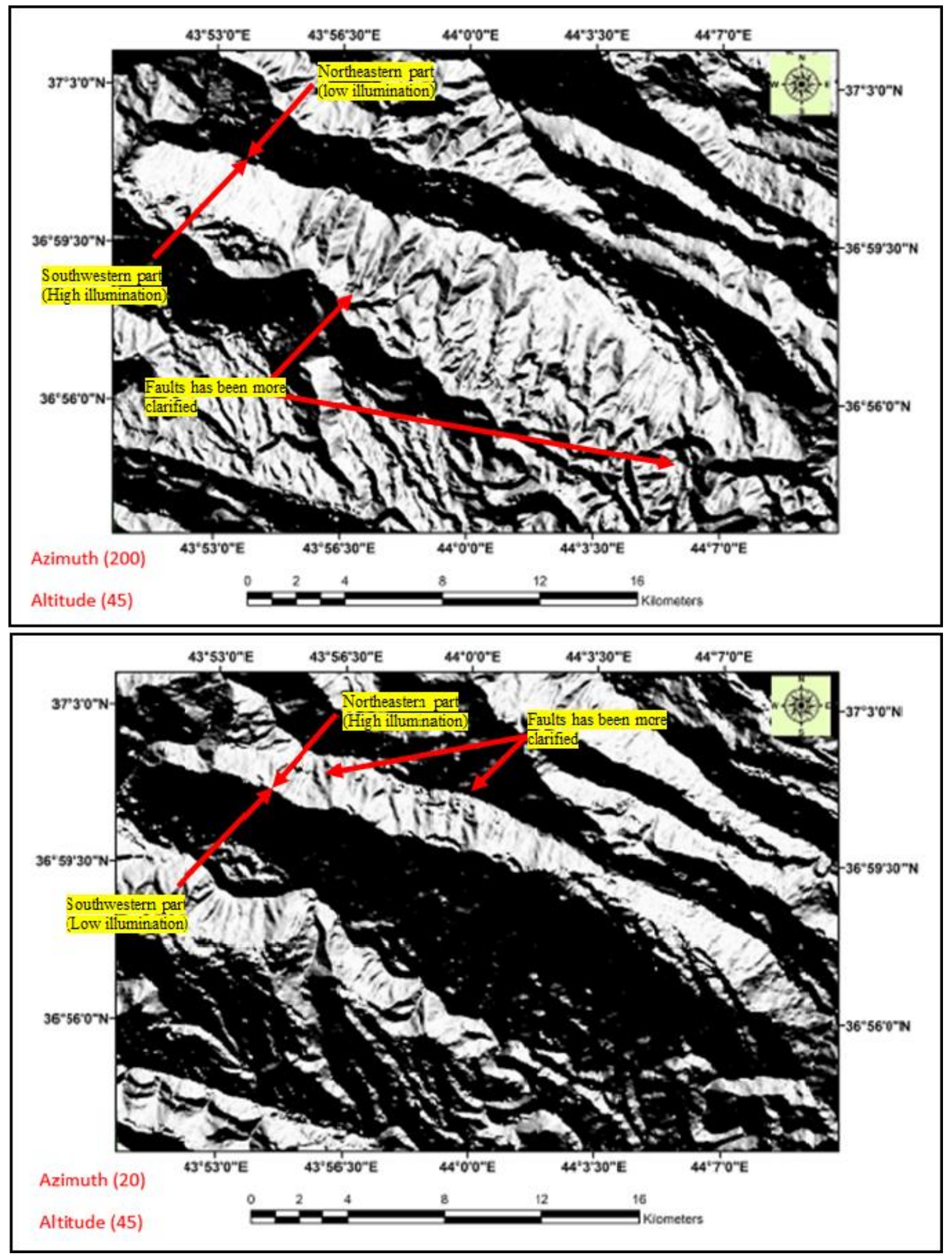

Fig. 9. Hillshade map of the study area 


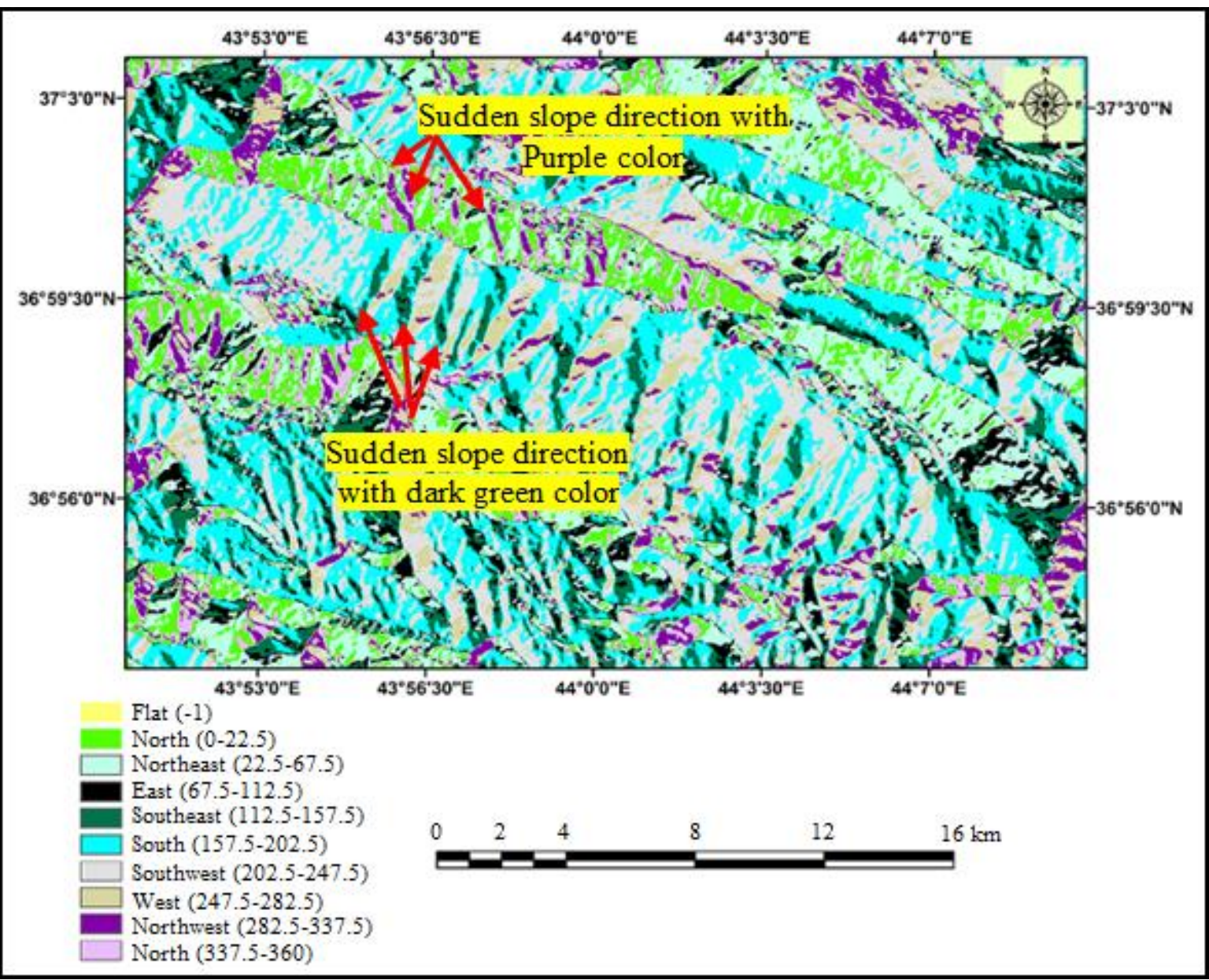

Fig. 10. Aspect map of the study area

\subsection{Curvature map}

The calculation of the curvature through the DEM is important in geomorphological studies; it determines the curvature of the shapes in the area and gives a comprehensive insight into features of topographic shapes (Purinton and Bookhagen, 2017). The maps are derived by calculating the curvature of the contour lines and determining their directions. The calculation of the curvature can result in shapes of concavity, or shapes of convexity (Price, 2010) have indicated that the numerical values resulting from the curvature derivation are expressed as follows:

1. The positive value of the curvature is associated with the convexity of the Earth's shape.

2. The negative value reflects the concavity of the shape.

3. A value equal to or close to zero indicates the straightness of the shape.

From Fig. 11, the following can be concluded:

A. The positive value reflects most parts of the structural ridges in the study area and the exposed surface shapes of the layers as triangular shapes, it corresponds in the direction with the inferred faults systems and begins to disappearance in the southwestern limb of the Shireen anticline, especially when moving towards the northwestern plunge. This confirms that the tectonic uplift is variant in the southwestern limb of the anticline. Variation can also be observed in the triangular area adjacent to the thrust fault and towards the core of the anticline.

B. The curvature map refers to the variation of erosion processes in the two limbs of the anticline. 

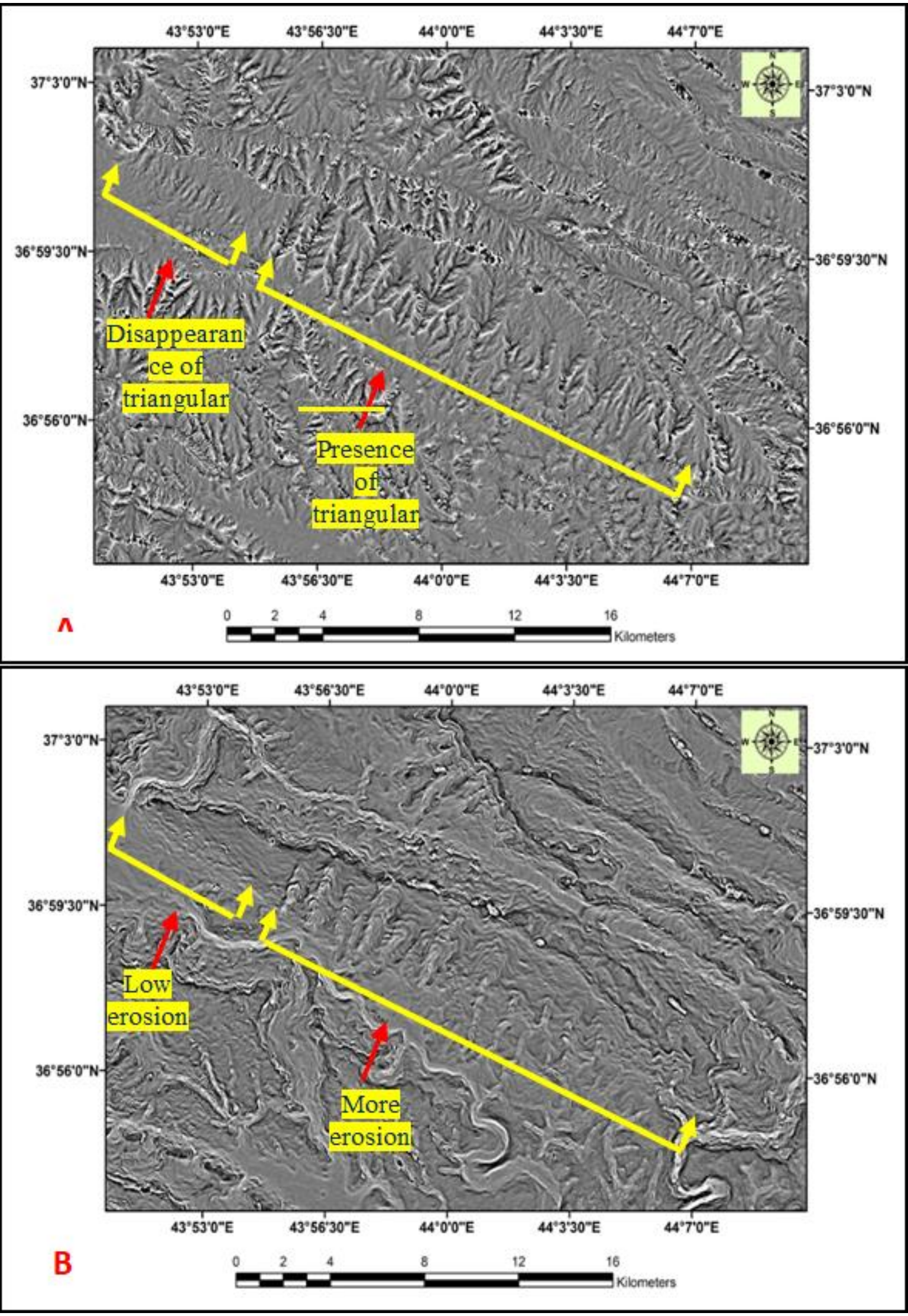

Fig. 11. Curvature map, A: output profile curvature; B: Output plane curvature 


\section{Analysis of Longitudinal Profile Analysis}

The analysis of longitudinal profiles is considered one of the important procedures in morphotectonic studies depending on the determination of the factors controlling the characteristics of the valleys and the areas they contain. These factors are lithology, zones of weakness, topography, hydrology vegetation, etc. Longitudinal profile analysis can determine the structural and tectonic setup of the stream valley and other influencing factors. The DEM was used to determine the heights of some stream's valleys selected in the two limbs of the Shireen anticline and draw it according to identified distances, (Fig. 12). Very steep or sudden slopes, known as knick points, were identified as clear uplifted form with steep anomalies as shown in the drawn valley section.

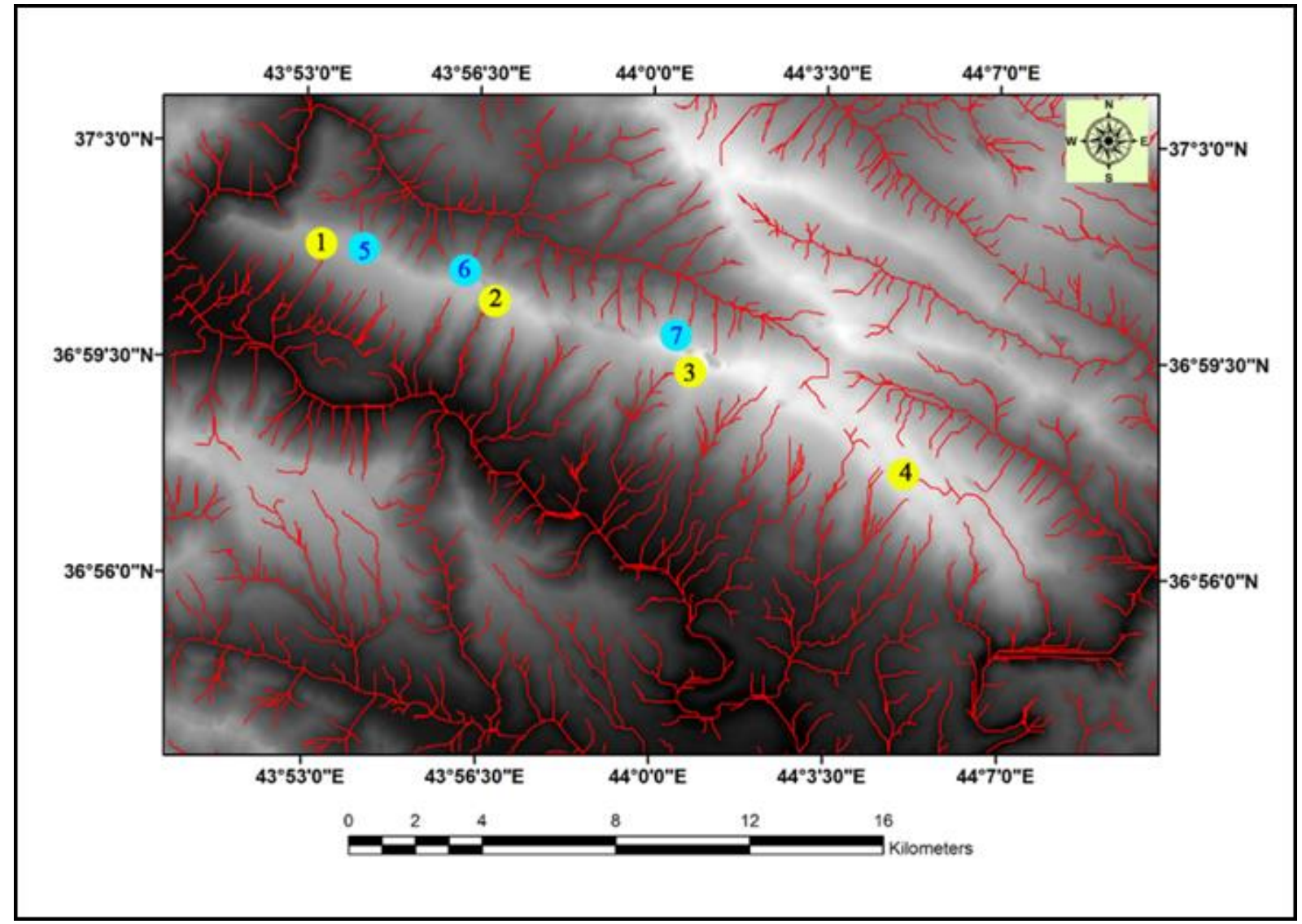

Fig. 12. The selected valleys locations on the applied longitudinal profile analysis

There are strong differences between the shapes of the longitudinal sections prepared by the DEM (Fig. 13), which provided detail morphotectonic information regarding the variation of the tectonic activity in the Shireen anticline. Some valleys have been selected within the two southwestern and northeastern limbs of the anticline, and longitudinal sections have been drawn (Fig. 12). The following provides an interpretation of the results obtained:

1. Four valleys were selected in the southwestern limb of the Shireen anticline and their longitudinal profiles were drawn starting from the highest uplifted areas to the meeting point with the valley course in the southern part of Shireen anticline (Fig. 12), and the slope is almost parallel to the axis of the anticline. The shape of the profile is not influenced much by the tectonic activity, and this is what was deduced from the shape of the longitudinal profile, which indicated a straight slope without the existence of convexities (Fig. 13-1). Furthermore, this part of the anticline is within a zone A in Fig. 7, and no faults or any displacement of the layers were identified. The actual initiation of the effect of the tectonic factor on the Shireen anticline is observed through the formation of convexities, especially when moving from the southwestern limb of the anticline towards the 
Foothill zone, (Fig. 13-2). While an improvement in the influence of the tectonic activity in the limb of the anticline and the Foothill zone is noted in Fig. 13-3, and this was also reflected in the direction of the sloping valley. Fig. 13-4 shows the higher influence of the tectonic activity through the processes of tectonic uplifting and the thrust fault that led to creating slope irregularities in the valley course, confirming that this area has been exposed to the highest tectonic activity.

2. It is noticed from the analysis of longitudinal profiles when moving to the northeastern limb that there is also a difference in the influence of the tectonic factor, the highest influence of the valley pattern is found within Fig. 13-5 and Fig. 13-6. This corresponds to what was previously inferred from the presence of certain faults affecting this part of the northeastern limb of the Shireen anticline.

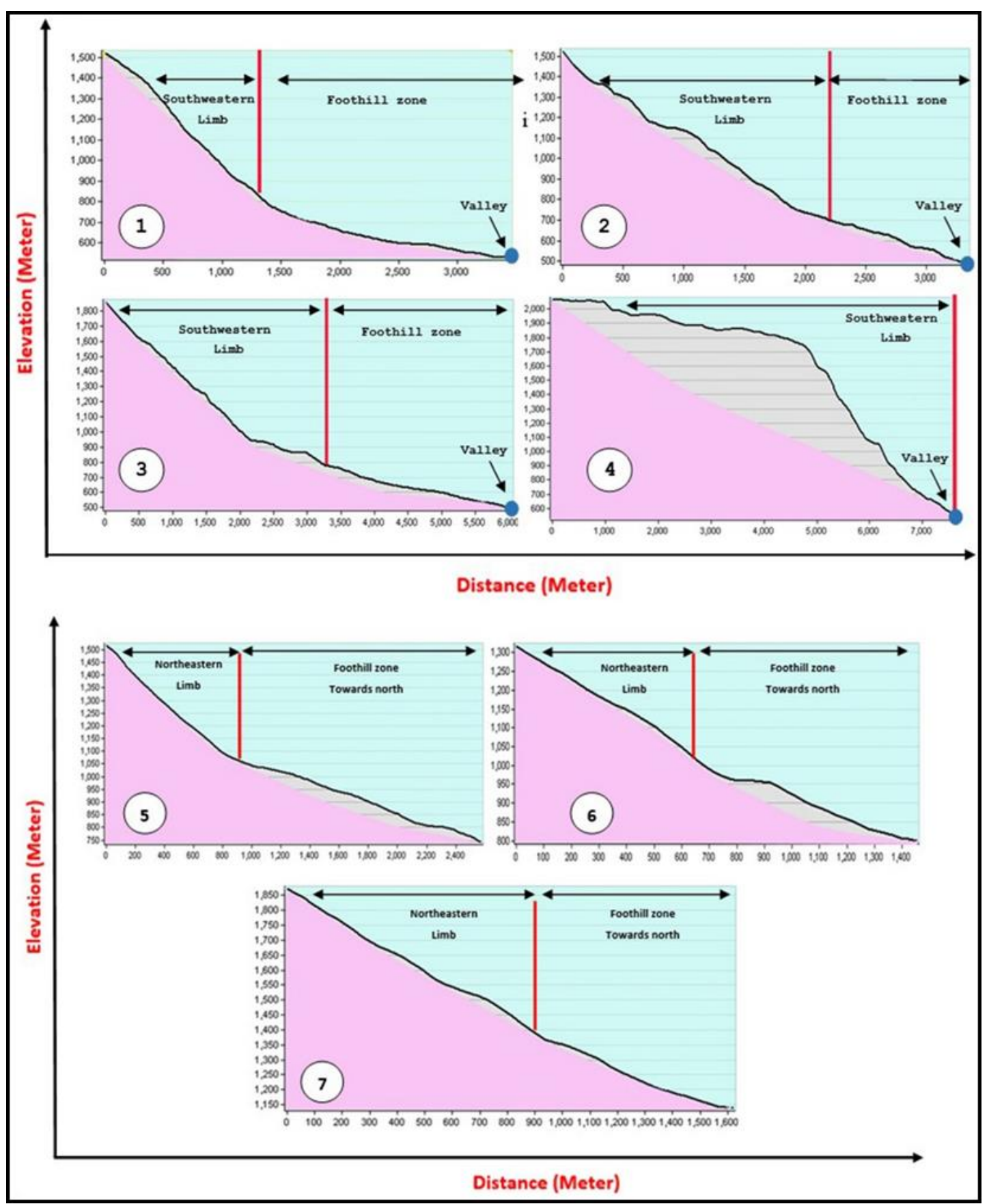

Fig. 13. Longitudinal profile analysis 


\section{Results and Discussions}

The current study involved extracting the morphotectonic features using the digital processing of Landsat image as well as the derivation of certain models from the DEM that covers the Shireen anticline. Because of the collision of the Arabian Plate with the Eurasian Plate (Numan, 2001; Agard et al., 2005; Othman and Jadda, 2020), the Shireen anticline showed certain morphotectonic properties due to the influence of different horizontal compressive stresses from the north and northeast. The results of the morphotectonic analysis revealed that there are several faults in the southwestern limb that have contributed to a clear displacement in the layers as well as an increase in the effect of tectonic uplift in this part of the anticline, which may have indicated that this limb has suffered extreme stresses relative to the northeastern limb. It is important to summarize what supports the extreme folding in the southwestern limb as follows:

- The existence of the reverse fault in some areas of the southwestern limb, as well as the strike-slip faults and joints, (Fig. 4).

- Sudden breaks of the layers along with the southwestern limb (Fig. 6).

- Tilting and rotation of the surfaces of flat iron topography profile (Fig. 7).

- Variations in incision rate of valleys sloping from the core of the anticline into areas of the southwestern limb (Fig. 13).

The morphodynamic change of the river pattern located to the southwest of the southwestern limb is parallel to the axis of the anticline. The river is highly sensitive to subtle changes in its grade caused by tectonic uplifting. An increase in river deflection around zones of tectonic uplift is observed as well as the abrupt shift in the river course and moving the river away from the southwestern limb in particular, in the areas that are characterized by the presence of several geological structures such as faults and joints Fig. 4. The morphotectonic features inferred from the analysis of the Shireen Anticline indicate that they are caused by the asymmetric movement on both sides of shallow structural faults in a northwest-southeast direction within the sedimentary cover (Ramthan et al., 2021), as well as variation of tectonic stresses is affecting the shape of the folds in northern Iraq (AL-Hachem, 2020). However, the previous studies concerning the analysis of tectonic stress indicated that the magnitude of the greatest compressive stress was in the direction of northeast-southwest and the perpendicularity of the greater tensile stress to it in the early stages of folding as a result of the oblique collision between the Arabian Plate and the Eurasian Plate, as well as the rotation of the Arabian Plate counterclockwise (Agard et al., 2005; Othman and Jadda, 2020). This results in a differential motion that can be theoretically illustrated by Fig. 14 in which the arcs represent shallow structural faults. The speed of rotation movement of the segments can be calculated from the principal components of rotational motion equations (5-8) Fig.15. In this context, because this study based on satellite data processing and DEM no practical calculations were applied to estimate the speed of rotational movement of these segments. In addition, this study referred to these equations for clarification that can be calculated in later studies through the availability of field data.

$$
\begin{aligned}
& s=r \varphi \ldots \ldots \ldots 5 \\
& v=r \omega \ldots \ldots .6 \\
& a=r \alpha=a_{t} \ldots \ldots \ldots 7 \\
& a_{n}=\omega^{2} r=\frac{v^{2}}{r} \quad \ldots \ldots \ldots 8
\end{aligned}
$$

Where:

$s$ : distance $r$ : radius $w$ : angular velocity $a$ : angular acceleration $v$ : velocity $a_{t}$ : tangential acceleration proportional to the radius $a_{n}$ : centripetal acceleration. 


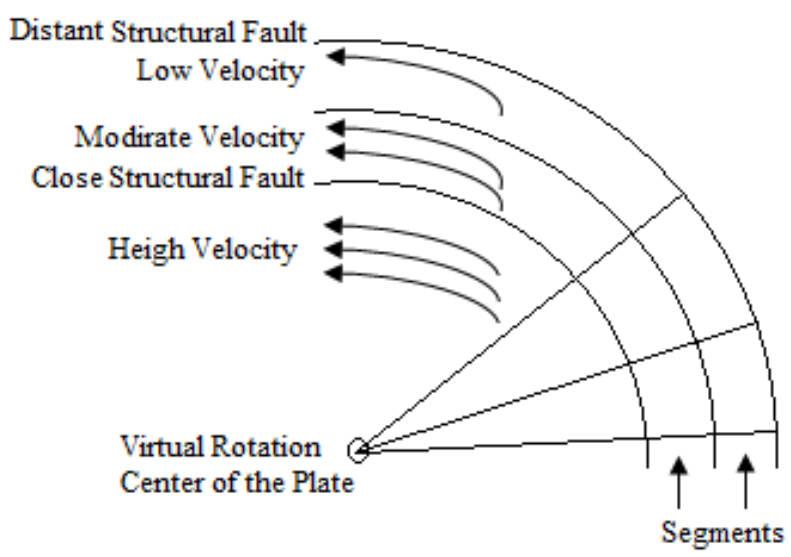

Fig. 14. Different rotations of segments confined between structural faults according to their remoteness to the center

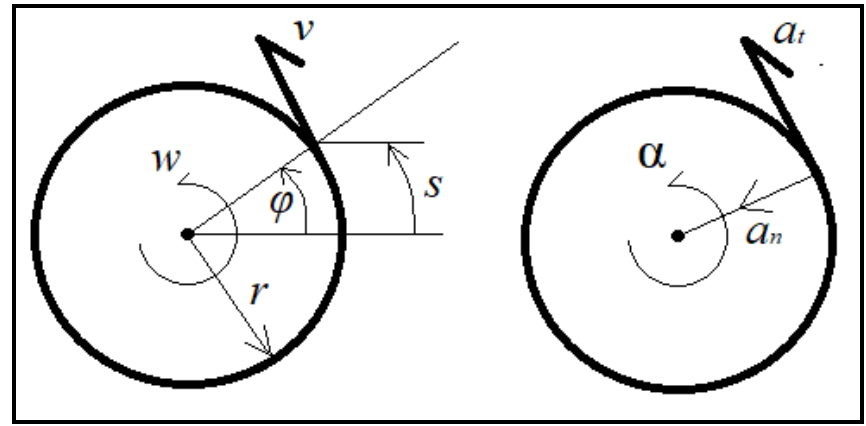

Fig. 15. Principal components of rotational motion

\section{Conclusions}

The morphotectonic characteristics are one of the most effective methods for analyzing tectonic and structural evidence that controlling to the hydrocarbon movement and trapping, as well as earthquakes. The current study showed the importance and efficiency of using multispectral satellite data and the DEM in extracting morphotectonic features. Through the application of digital processing methods, represented by image filtering, the edges of the land features are enhanced, which can give information about morphotectonics. This is shown through the kernel filter, which led to the identification of the zone of weakness in the study area. Also, the enhancement with the Principal Components Analyses (PCA) can lead to an increase in the clarity of morphotectonic features by decorrelation with the spectral bands using within the satellite. The chromatic combination of these components gives important details about the morphotectonic units. On the other hand, the efficiency of extracting morphotectonic features can be increased by integrating with special models derived from digital elevation data such as TIN, Hill Shade, Aspect, and Curvature. Each image gave a unique style to extract the morphotectonic features. This study was relied on analyzing the longitudinal profiles by selecting valleys on both limbs of the anticline and calculating the knick points that gave evidence of the tectonic factor's impact on the anticline by calculating the sudden slopes of those valleys. These slopes gave further evidence that the anticline was affected by tectonic activity. Because the current study was focused on the satellite data processing and DEM the authors formulate specific equations that could give quantitative values showing the effect of tectonic activity on the anticline. These quantitative values can be used in further detailed studies when field data are available and relevant to the displacement measurements of the inferred morphotectonic features in the current study. 


\section{Acknowledgements}

The authors are grateful to acknowledge the assistance of the University of Mosul, Mosul, Iraq for the support to complete this work. For much fertile cooperation on completing this work, we thank our colleagues in the Remote Sensing Center, Dams and Water Resources Research Center, and College of Petroleum and Mining Engineering. The authors are very grateful to the reviewers, Editor in Chief Prof. Dr. Salih M. Awadh, the Secretary of Journal Mr. Samir R. Hijab, and the Technical Editors for their great efforts and valuable comments.

\section{References}

Abdu, H. A., 2019. Classification accuracy and trend assessments of land cover-land use changes from principal components of land satellite images, International Journal of Remote Sensing, 40 (4), 1275-1300.

Agard, P, Omrani, J., Jolivet, O., and Mouthereau, F., 2005. Convergence history across Zagros (Iran): constraints from collisional and earlier deformation, International Journal of Earth Sciences, 94 (3), 401-419.

Al-Amri, S. S., Kalyankar, N. V., and Khamitkar, S. D.,2010. A comparative study of removal noise from remote sensing image, IJCSI International Journal of Computer Science Issues, 7(1), 32-36.

AL-Hachem, A. E. K., 2020. Paleostress analysis of Chia Gara structure in Dohuk Area, Northern Iraq, Iraqi Journal of Science, 61(6), 1383-1391.

Alavi, M., 2004. Regional stratigraphy of the Zagros fold-thrust belt of Iran and its proforeland evolution, American Journal of Science, 304 (1), 1-20.

Alexandris, N., Gupta, S., and Koutsias, N., 2017. Remote sensing of burned areas via PCA, Part 1; centering, scaling and EVD vs SVD, Open Geospatial Data, Software and Standards, 2 (1), 1-11.

Anderson, R. S., and MacGregor, K. C., 1998. The role of glacial erosion in mountain range evolution, EOS (Transactions of the American Geophysical Union), 79, 337.

Berberian, M., 1981. Continental Deformation in the Iranian Plateau, Science. University of Cambridge, 296, $5575,699$.

Biland, J., and Çöltekin, A., 2017. An empirical assessment of the impact of the light direction on the relief inversion effect in shaded relief maps: NNW is better than NW, Cartography and Geographic Information Science, 44 (4), 358-372.

Caixeta, F. F., 2016. An evaluation of Multiple Endmember Spectral Mixture Analysis applied to Landsat 8 OLI images for mapping land cover in southern Africa's Savanna'. MSc. Thesis, University of Louisville, 55 pp.

Champagnac, J., Peter, M., Christian, S., and Frédéric, H., 2012. Tectonics, climate, and mountain topography, Journal of Geophysical Research: Solid Earth, 117, (B2), 1-34.

Fawwaz, I., Zarlis, M., and Rahmat, R. F., 2018. The edge detection enhancement on satellite image using bilateral filter, MS\&E, 308 (1), 120-152.

Fouad, S. F. A., 2015. Tectonic Map of Iraq, Scale $1: 1000$ 000, Iraqi Bulletin of Geology and Mining, 11 (1), 1-7.

Hamdoon, A. N., Znad, R. K. and Adeeb, H. G. M., 2021. Structural analysis and morphotectonic interpretation of Ain Sifni Anticline, Northern Iraq, Iraqi Geological Journal, 49-59.

Ismail, T., 2014. Extraction Of Geographic Features Of Specific Nature From Satellite Images By Segmentation, MSc. Thesis, Damascus University, Syria, $97 \mathrm{pp}$.

Jassim, S. Z., and Goff, J. C., 2006. Geology of Iraq, 1st. Edited by Lea Novotna. Dolin, Hlavni 2732, Prague and Moravian Museum, Zelny trh 6, Brno, Czech Republic, 362 pp.

Kaya, Ş., and Tüysüz, O., 2015. Using digital elevation model and remotely sensed data in determining the geomorphological and morphometric features: Gaziköy-Saros Region, Northwestern, International Journal of Environment and Geoinformatics, 2 (2), 1-15.

Lakshmi, S. E., and Yarrakula, K., 2018. Review and critical analysis on digital elevation models, Geofizika, 35 (2), 129-157.

Liu, H., and Wu, C., 2020. Developing a Scene-Based Triangulated Irregular Network (TIN) Technique for Individual Tree Crown Reconstruction with LiDAR Data, Forests, 11(28). 
Mahmood, S. A., Waheed, Z., Batool, H., Ghazi, S., Mirza, A., Akhtar, S., Raza, H., and Khan, A., 2014. Remote sensing and morphotectonic analysis in Hazara Kashmir Syntaxis using river longitudinal profiles, Geodynamics Research International Bulletin, 2, 01.

Mather, P. M., and Koch, M., 2011. Computer processing of remotely-sensed images: an introduction. John Wiley \& Sons, https://doi.org/10.2307/633899.

Numan, N. M. S., 2001. Cretaceous and Tertiary Alpine subductional history in northern Iraq, Iraqi Journal of Earth Science, 1 (2), 59-74.

Othman, B. S., and Jadda, Z. Q., 2020. Paleostress analysis of the northeastern limb of pulkhana anticline, NE Iraq: Implications for arabian plate tectonic evolution, Iraqi Journal of Science, 61 (11), 2936-2963.

Price, M. H., 2010. Mastering ArcGIS, McGraw-Hill, New York, 607 pp.

Purinton, B., and Bookhagen, B., 2017. Validation of digital elevation models (DEMs) and comparison of geomorphic metrics on the southern Central Andean Plateau, Earth Surface Dynamics, 5 (2), 211-237.

Ramsey, L. A., Walker, R. T., and Jackson, J., 2008. Fold evolution and drainage development in the Zagros mountains of Fars province, SE Iran, Basin Research, 20 (1), 23-48.

Ramthan, A.W. Abdulnaby, N. Abd, Mahdi, H. and Al-Shukri, H., 2021. A subsurface geologic feature inferred from relocation of local earthquakes in Al- Refaei District, Southern Iraq, 54 (1A), 35-43.

Ruibo, W., and Weiming, C., 2009. Extraction of tectonic faults of longmen mountain based on DEM, in 2009 2nd International Congress on Image and Signal Processing, ISBN: 1424441293.

Thannoun, R., 2012. Structural control evaluation of hydrocarbon seepages in Northern Iraq using remote sensing techniques, Unpublished Ph. D. Thesis, College of Science, Geology Dept. Mosul University, $222 \mathrm{pp}$.

Ton, J., and Jain, A. K., 1989. Registering landsat images by point matching, IEEE Transactions on Geoscience and Remote Sensing, 27 (5), 642-651.

Vivoni, E. R. Vivoni, E. R., Ivanov, V. Y., Bras, R. L., and Entekhabi, D., 2004. Generation of triangulated irregular networks based on hydrological similarity, Journal of hydrologic engineering, 9 (4), 288-302.

Wang, J., Ge, Y., Heuvelink, G. B. M., Zhou, C., and Brus, D., 2012. Effect of the sampling design of ground control points on the geometric correction of remotely sensed imagery, International Journal of Applied Earth Observation and Geoinformation, 18, 91-100.

Whittaker, A. C., 2012. How do landscapes record tectonics and climate?, Lithosphere,4(2), 160-164.

Znad, R. K. H., Mostafa, S. E., and Al-Sumaidaie, M. A. H., 2020. Effect of tectonic setting on distribution of pelagic sediment unit (Shiranish Formation) in Zagros Foreland Basin, Iraqi Segment, Iraqi Geological Journal, 53 (2A), 105-119. 